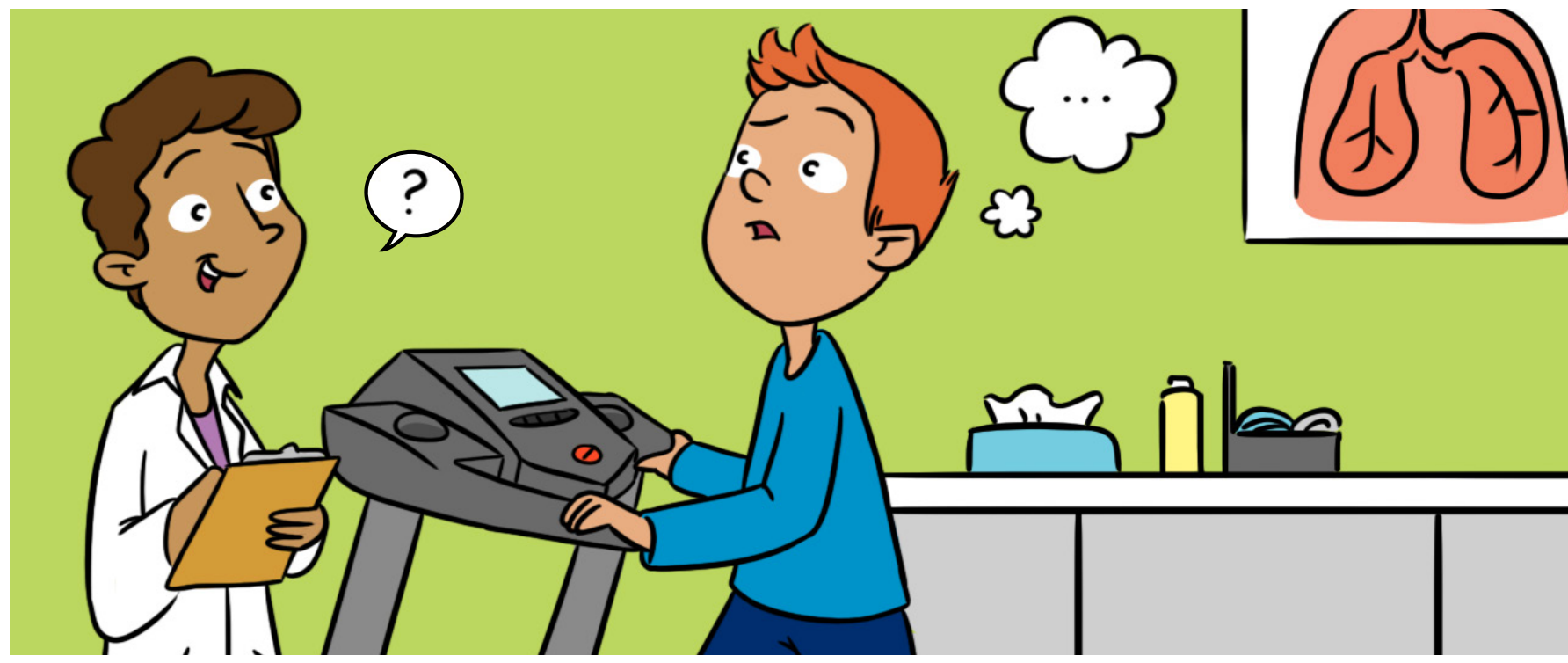

\title{
WHY IS IT DIFFICULT TO CROSS THE STREET WHILE TALKING?
}

\section{Sabine Schaefer*}

Saarland University, Saarbrücken, Germany

REVIEWED BY:

CHRISTINA

SEIX

ACADEMY

AGE: 9-10
In everyday life, we often do a task with our body (like walking or running), while we talk to someone or think about something else. This can sometimes cause problems, especially when the tasks are very difficult, or when they are not well-practiced. Researchers are interested in how people perform tasks at the same time, and also in age differences: Do children and older adults encounter more problems in such situations than young adults? Findings indicate that children and older adults tend to pay more attention to the motor task when there is a risk of getting hurt, which is a smart strategy because it keeps them safe.

There are many situations in which you think about something or talk to somebody while you do some movement with your body at the same time. For example, you might talk about your homework with your friend while walking to school. Or you might ride your bike while listening to music. At first sight, these situations do not seem to be tricky, and you have probably done such things many times in your life. But what happens when you need to cross a busy street on your way to school? Maybe you will stop talking for a while and focus your attention on the traffic, so that you can reach the other side of the street safely. Researchers who are interested in the relationship 


\section{COGNITION}

Thinking.

\section{FIGURE 1}

Cognitive changes during life. Young adults perform better than children or older adults. Changes are more pronounced in fluid intelligence (e.g., reacting quickly, ignoring distractions) than in crystallized intelligence (e.g., recalling information that one has learned in the past). between thinking and moving often ask people to perform tasks with both thinking and moving components in a laboratory. The researchers want to find out whether people's performances on the movement task or the thinking task or both get worse when they need to do two things at the same time. Sometimes, the researchers also want to find out whether children can do two tasks at the same time just as well as young adults, or whether older adults have more difficulties with these tasks than young adults do.

\section{THINKING AND MOVING CHANGES WITH AGE}

Cognition means "thinking," and cognition is always needed when you use your brain to solve a task. For example, you are using cognition when you think hard about the correct solution to a math question, or when you try to remember the name of your friend's sister, or when you think about whom to invite to your birthday party. The ability to perform tasks that use cognition changes over the course of your life. Children become a lot better at such tasks the older they get, young adults usually perform at the highest level, and in older adulthood, performance deteriorates again. Figure 1 shows the results of a study that tested 356 participants from 6 to 89 years of age [1]. Participants had to do all sorts of cognition tasks. For example, they were asked to name as many four-legged animals as possible, to search for specific small objects among many other distracting objects on a computer screen, to react as quickly as possibly when a certain symbol appeared on the screen, to memorize lists of word combinations, and much more. The researchers grouped the tasks into categories and calculated the scores for people in each age group. The research showed that young adults performed best. They also found that performance on cognition tasks improves during childhood and gets worse as adults get older. Figure 1 also shows that different tasks show different results in terms of how they change during child development and aging. For some tasks, older adults still perform rather well (for example, when recalling information that they learned a

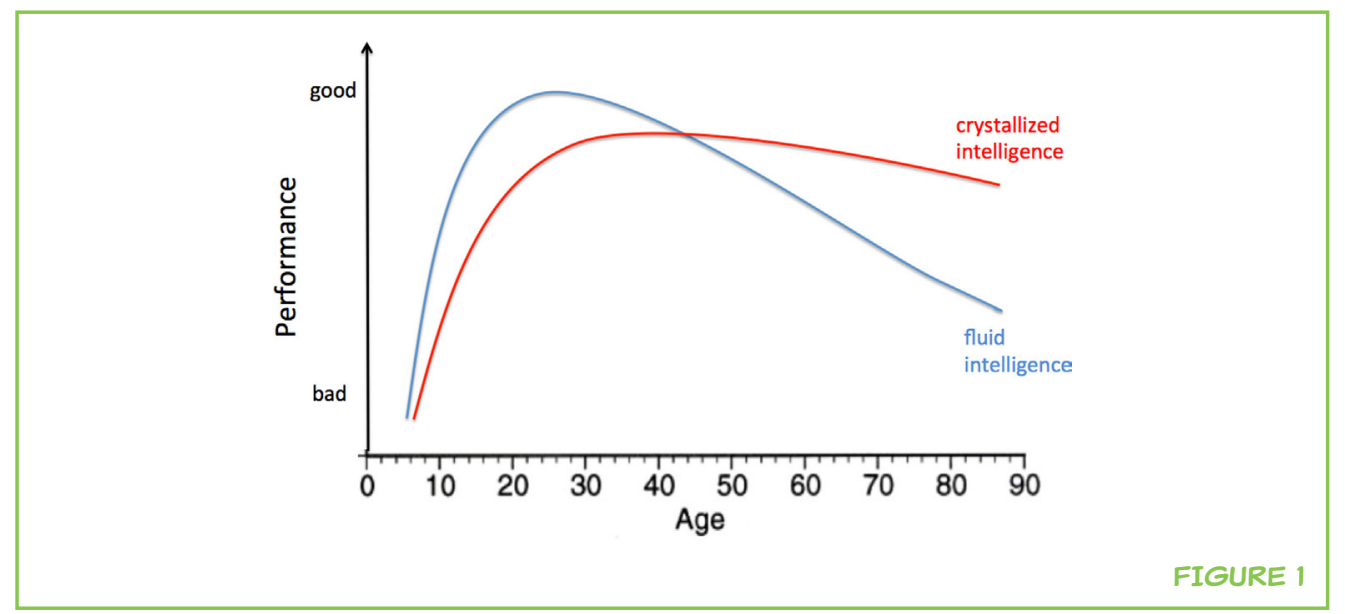


long time ago $=$ crystallized intelligence) but in other tasks, adults start having problems even at a fairly young age (for example, when focusing their attention on somebody who talks in a very crowded and noisy room $=$ fluid intelligence). During childhood, on the other hand, children learn tasks very quickly-a child in grade 5 usually knows a lot more and reacts a lot more quickly than a child in grade 2 .

But what about movement? Does this also change during development and aging? Figure 2 shows a very similar pattern to Figure 1, but in this case, the 338 participants were asked to place bricks on top of each other, to throw a bean bag at a target, to walk on a straight line as quickly as possible by always placing the front heel against the toes of the back foot, or to run in slopes around obstacles [2]. The researchers who performed this study tested 7- to 9 -year-old as well as age groups from 19 to 80 years old. Scores were averaged across the tasks. Again, young adults performed better than did children and older adults, resulting in a similar pattern or results as we saw with the cognitive tasks.

\section{PERFORMING THINKING AND MOVING TASKS CONCURRENTLY}

So, apparently, cognitive and movement tasks are more demanding for older adults compared with young adults. What happens if study participants need to do the two things at the same time? For example, what if they have to walk on a treadmill or on a narrow track and at the same time listen to a stream of numbers and then identify whether a certain number is identical to the number 2 positions earlier (called 2-back)? Figure 3 shows an example of this task. As you can image, it is rather difficult. Researchers first had to look at the results from people doing only one task at a time (walking only, or doing 2-back while sitting still), and then compare these results to the

FIGURE 2

Performance on movement tasks is best in young adulthood.

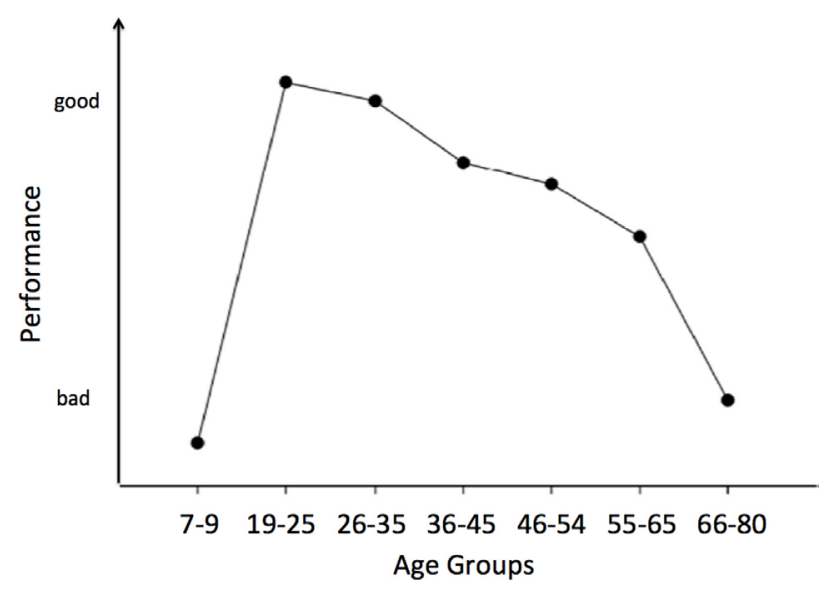

FIGURE 2 
DUAL-TASK COSTS

Changes in performance caused by the additional task.
FIGURE 3

An example of a 2-back task. The task has been used as a cognitive task in dual-task studies. Participants hear a stream of numbers and have to compare the current number to the number presented two positions earlier.

results they got when people tried to do both tasks together [3]. By looking at both scenarios, the researchers were able to calculate something called dual-task costs. These costs told the researchers whether performance at either the thinking task or the movement task got worse when the two tasks were performed together, and also whether performance deteriorated more in the movement task or the thinking task [4]. The researchers found that older adults had higher dual-task costs than young adults. The older adults also tended to maintain their motor performance at the expense of their cognitive performance. In other words, when the thinking task became very difficult, they focused their attention on walking or on keeping their balance. To use the "walking while talking" example we described earlier, when older adults approach a busy street intersection, it is more important for them to reach the other side of the road safely than it is for them to continue their conversation while they walk. This makes sense, because if they did not pay attention to walking, they could stumble and fall. This can be very bad for older adults, because they could end up in the hospital with a broken bone. So, it is smart for older adults to pay more attention to walking and keeping their balance than to continuing their conversation.

Are similar results seen with children? Children already perform worse than young adults in motor and cognitive tasks when they are asked to do one of the tasks at a time. And when children need to do both tasks at once, they usually show poorer performance in the thinking tasks than when they are doing only one task at a time. This can be observed as recalling fewer words in a memory task or missing more targets in a 2-back task. The movement task often suffers as well. The way children walk on a treadmill can become unsteady, or they might walk slower on a track when they are doing both tasks at once. However, sometimes children can improve their performances when they do both tasks together. When balancing on a wobbly board while trying to remember word lists or while working on 2-back, they swayed less than they did when they were just trying to balance without performing the mental task [5]. This result indicates that children also focus more strongly on their movements in challenging situations, just like older adults do. Since the children were already swaying a lot when they were just trying to balance, 
and probably would have fallen off the wobbly board if they swayed any more, they simply reduced their sway and accepted the higher costs in their cognition-meaning they did worse on the cognitive task. This was a smart choice, was not it? In another study, children were asked to do 1-2-, 3-, and 4-back (very difficult!) while walking on a treadmill. Each child could choose how fast the treadmill moved, so that their walking speed felt very comfortable. Under these circumstances, children showed better cognitive performances while walking as compared with doing the task while sitting. Apparently, moving around can sometimes help children to think. Maybe you have experienced this as well... Some people like to walk around the room when learning vocabulary. And movement or exercise during a school break can also help you focus in the upcoming class.

\section{THE INFLUENCE OF PRACTICE}

What about practice? Would it be easier to combine a cognitive and a movement task if you practice one of the two tasks? Studies have shown that this seems to be true. When you learn a new physical skill, you initially have to pay attention to everything you do. For example, when learning to ride a bike, you have to focus on how to turn, how to keep your balance, and how to pedal in a coordinated way. After a while, and with more practice, you do not have to focus on all these little steps anymore. You automatically do them in the correct way. Your performance is sometimes even better when you do not pay attention, because otherwise you might overreact and not ride your bike so smoothly. There are studies that compared people who have a lot of experience in a certain sport (for example, golf putting experts) to people who have never done that sport (called novices). Both experts and novices were asked to do a cognitive task while putting, for example, counting backward in steps of three from the number 267. Sounds difficult, does not it? But the experts showed an even better putting performance. The novices had a very hard time, and their putting performance was even worse than it was without the cognitive task.

DUAL-TASK

Performing two tasks concurrently.
Table 1 shows several things that can influence dual-task performances. In everyday life, you probably do not always think about an ideal strategy when facing a dual-task situation. And most of the time, you automatically do the right thing-you focus your attention on the task that can be risky or harmful if you do not pay enough attention to it. Just like your grandparents do. However, there might be situations when you underestimate dangers. It is not a good idea to use a mobile phone while driving a car, while bicycling through heavy traffic, or even while crossing a busy street on foot. And older adults may not realize that they are no longer able to do things that used to be easy for them ten years ago. So, hopefully, future research will identify such situations and help people recognize them to avoid unnecessary risk-taking, accidents, and injuries. 


\section{TABLE 1}

Factors that influence dual-task performances.

\begin{tabular}{ll} 
Factor & Observed effects \\
\hline Age & $\begin{array}{l}\text { Children and older adults often have more } \\
\text { problems in demanding dual-task situations than } \\
\text { young adults do, but there are exceptions }\end{array}$ \\
\hline Task combinations & $\begin{array}{l}\text { Some tasks are easier to perform concurrently than } \\
\text { others. If both tasks require a lot of attention, }\end{array}$ \\
& performance in both tasks might decrease \\
\hline Practice & A well-practiced task can be combined more easily \\
& with another task, because it runs "automatically" \\
\hline Task difficulty & A more difficult task will require more attention and \\
& cause larger dual-task costs \\
\hline Risk & Sometimes it makes sense to focus more on one \\
& task than on the other, especially if the motor task \\
involves a risk of getting hurt
\end{tabular}

TABLE 1

\section{REFERENCES}

1. Li, S. -C., Lindenberger, U., Hommel, B., Aschersleben, G., Prinz, W., and Baltes, P. B. 2004. Transformations in the couplings among intellectual abilities and constituent cognitive processes across the life span. Psychol. Sci. 15:155-63. doi:10.1111/j.0956-7976.2004.01503003.x

2. Leversen, J. S. R., Haga, M., and Sigmundsson, H.. From children to adults: motor performance across the life-span. PLoS One (2012) 7:e38830. doi:10.1371/journal. pone.0038830

3. Schaefer, S. 2014. The ecological approach to cognitive-motor dual-tasking: findings on the effects of expertise and age. Front. Psychol. 5:1167. doi:10.3389/ fpsyg.2014.01167

4. Guttentag, R. E. 1989. Age differences in dual-task performance: procedures, assumptions, and results. Dev. Rev. 9:146-70. doi:10.1016/0273-2297(89)90027-0

5. Schaefer, S., Krampe, R. T., Lindenberger, U., and Baltes, P. B. 2008. Age differences between children and young adults in the dynamics of dual-task prioritization: body (balance) versus mind (memory). Dev. Psychol. 44:747-57. doi:10.1037/0012-1649.44.3.747

SUBMITTED: 14 November 2018; ACCEPTED: 12 June 2018; PUBLISHED ONLINE: 29 June 2018.

EDITED BY: Sabine Kastner, Princeton University, United States

CITATION: Schaefer S (2018) Why Is It Difficult to Cross the Street While Talking? Front. Young Minds 6:30. doi:10.3389/frym.2018.00030

CONFLICT OF INTEREST STATEMENT: The author declares that the research was conducted in the absence of any commercial or financial relationships that could be construed as a potential conflict of interest. 


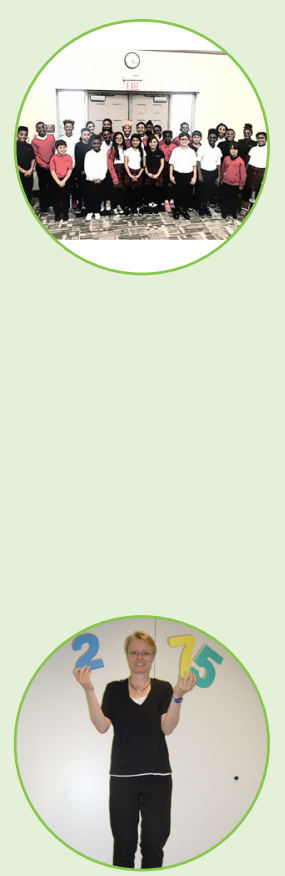

COPYRIGHT ( 2018 Schaefer. This is an open-access article distributed under the terms of the Creative Commons Attribution License (CC BY). The use, distribution or reproduction in other forums is permitted, provided the original author(s) and the copyright owner are credited and that the original publication in this journal is cited, in accordance with accepted academic practice. No use, distribution or reproduction is permitted which does not comply with these terms.

\section{REVIEWED BY}

\section{CHRISTINA SEIX ACADEMY, AGE: 9-10}

CSA is an innovative urban Pre-K-8 independent school focused on providing students from underserved communities with a holistic education, critical habits of mind, and an engaging learning environment. A scholarship is awarded to every child entering the academy to cover tuition, books, school uniforms, meals, door to door transportation, as well as room and board for students that choose to board in 4-8th grade. Our goal is to ensure that all students move from "Potential to Achievement" and graduate inspired to "Pay it Forward" like our Founder, Christina Seix.

\section{AUTHOR}

\section{SABINE SCHAEFER}

I am a psychologist working in the Sports Science Institute of Saarland University in Germany. In my research, I often ask children and younger or older adults to perform a movement task and a thinking task at the same time. For example, participants are asked to walk on a narrow track while memorizing word lists. I want to find out when such dualtask situations make a person perform worse, and when they make him or her perform better. I have also trained older adults on stationary bicycles to investigate whether improved fitness leads to changes in thinking and in the brain. *sabine.schaefer@uni-saarland.de 